\title{
Raptor Diversity and their Assessment in Listed Areas around Yavatmal City, Maharashtra, Central India
}

\author{
Praveen Joshi \\ Department of Zoology,Amolakchand Mahavidyalaya,Yavatmal.445001, Maharashtra, India
}

\begin{abstract}
The present paper have discusses the diversity and assessment of raptors in the two forest, five fresh water bodies and their surroundings of Yavatmal city, Maharashtra, central India. Twenty raptors are belonging to Accipitridae family recorded during the study period from Dec. 2014 to Dec. 2015. (Table-1) The two species Sikra and White-eye buzzard have the highest population where the Grey headed fish eagle, Black eagle, Besra, Peregrine falcon, Osprey and Eurasian hobby were rarely observed. The highest population was sighted in the forest area followed by wetland, cultivated land and lastly unplowed lands, all the remaining results are mention in the Table-2 and Graph-1 and Graph-2. The findings has used for analyzing the Shannon-Wiener function formula and result are the species diversity (H-2.35), maximum diversity (Hmax-2.99) and evenness (J-0.78). The formula are implemented individually to selected habitat and results are indicates that FA having Species diversity (H-2.31), maximum diversity (Hmax-2.99) and evenness (E-0.77). WL -Species diversity (H-2.62), maximum diversity (Hmax-2.99) and evenness (E-0.87), UL-Species diversity ( H- 1.85), maximum diversity (Hmax-2.99) and evenness (E-0.61). CL-Species diversity (H-1.81), maximum diversity, (Hmax-2.99) and evenness (E-0.60). (Table-1 and Table2). The primary results will provide base line data that helps to motivate the study of occurrence and flyways migration pattern of raptors over the fresh water bodies and forest of Yavatmal city and their surrounding area, Central Asia. The study indicates that selected habitats are fulfilling all the needs of raptors in different seasons. In the future, we will focus on specific habitat selection of the species and create correlation with their occurrence. The number is not satisfactory compare to study area so it is necessary to find the causes regarding number of raptors and suggest fruitful ideas in the conservation of habitat and which helps automatically to increase the number of raptors in the area.
\end{abstract}

Keywords: Raptor, diversity, Shannon index, fresh water resources, and forest

\section{Introduction}

The term raptor used for all birds of prey, the most significant characteristics that differentiate raptors from other birds that hunt or take live prey. India has perhaps the largest array of environmental situations by way of her geographical location, varied physical features and climatic types, and displays the widest variety of biomass. Among the roughly 292 to 313 species of diurnal birds of prey worldwide in the order falconiformes, India's varied biogeographical zones support an impressive diversity of 69 resident and migratory raptor species, a total of 104 forms including subspecies and races. They feed on the full gamut of available prey like insects, fish, snakes and birds. Diversity of raptors are one of the most important ecological indicators to evaluate the quality of habitats. Present situation indicates that avifaunal diversity has been decreasing due to the destruction of natural habitats and anthropogenic disturbances. Number of species of birds may be no alternative to inhabit in the urban areas. The present study based finding and records of raptors in the selected area, which is covers almost twenty kilometers around Yavatmal city, and prepare first data base line and their assessment in the given area.

\section{Materials and Methods}

The listed area having Forest, Wet Land, Unplowed Land and Cultivated Land that are around water bodies of Yavatmal city. Observations and sighting records of birds were taken from whole area. Weekly visits were organized to selected range for observations, during the period from Dec. 2014 to Dec. 2015.

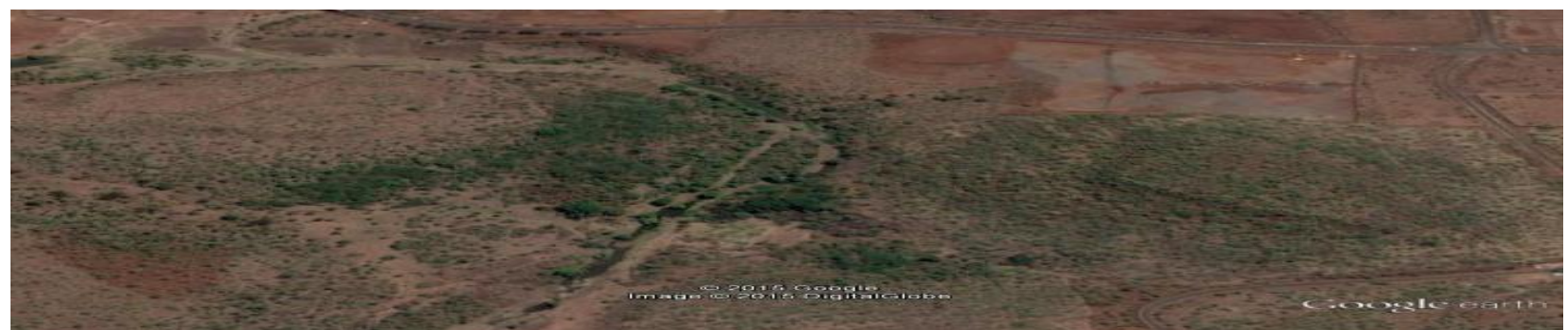

Figure 1: Location of Bahiram Forest-20021'07.97'- $78^{0} 06^{\prime} 28.04^{\prime \prime}$. 


\section{International Journal of Science and Research (IJSR) \\ ISSN (Online): 2319-7064}

Index Copernicus Value (2013): 6.14 | Impact Factor (2015): 6.391

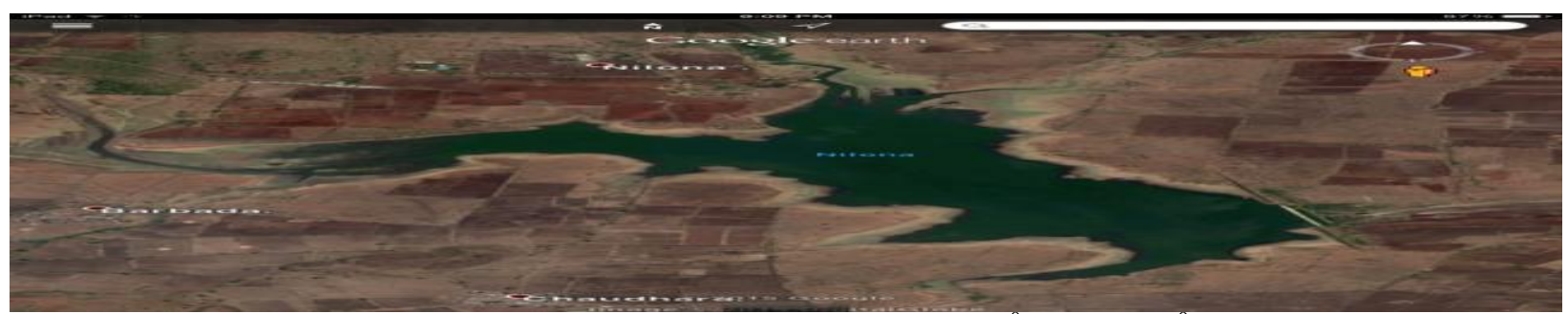

Figure 2: Location of Nilona Dam(Medium Project)- $78^{0}-8^{\prime}-32^{\prime \prime}-20^{0}-23^{\prime}-10^{\prime \prime}$

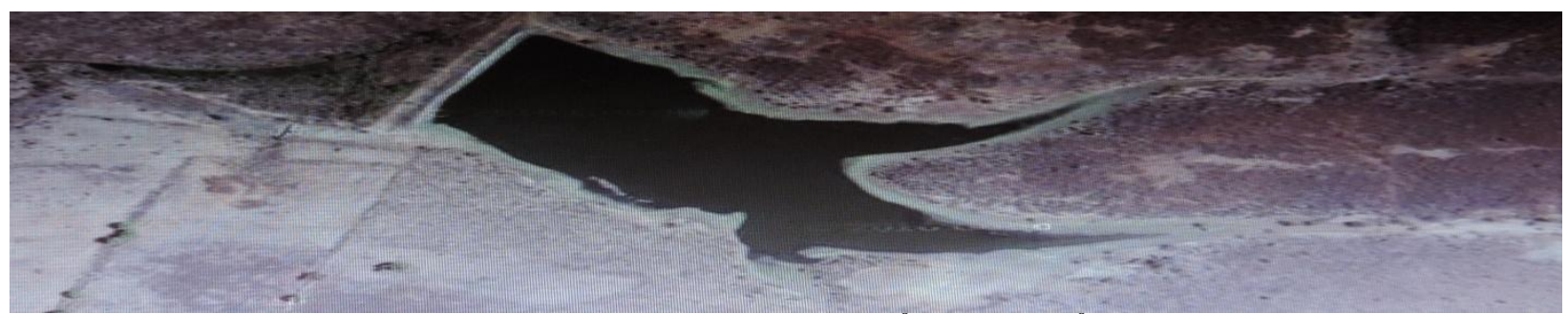

Figure 3: Location of Echori Forest $-77^{0}-2$ '-14 ' $-20^{0}-3$ '-16”

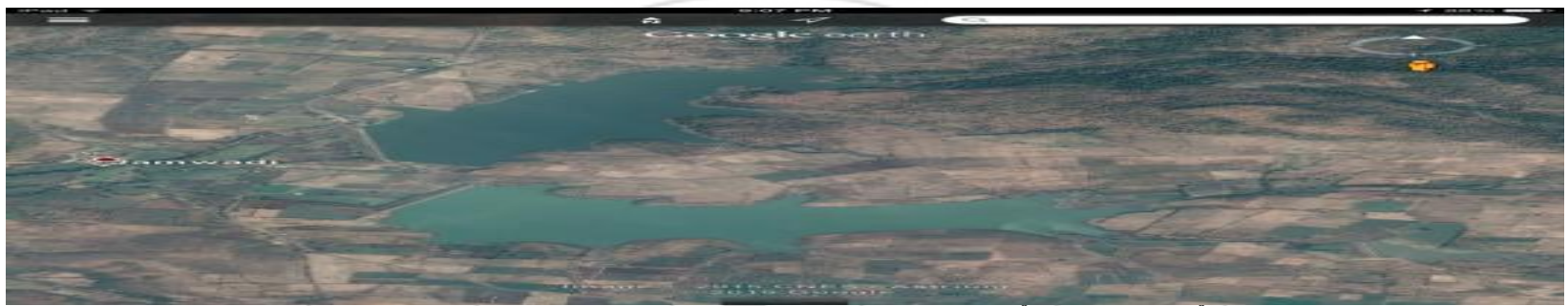

Figure 4: Location of Jamwadi Dam(Medium Project) $-77^{0}-1$ '-1/2"'-20 -1 '-1/4"'

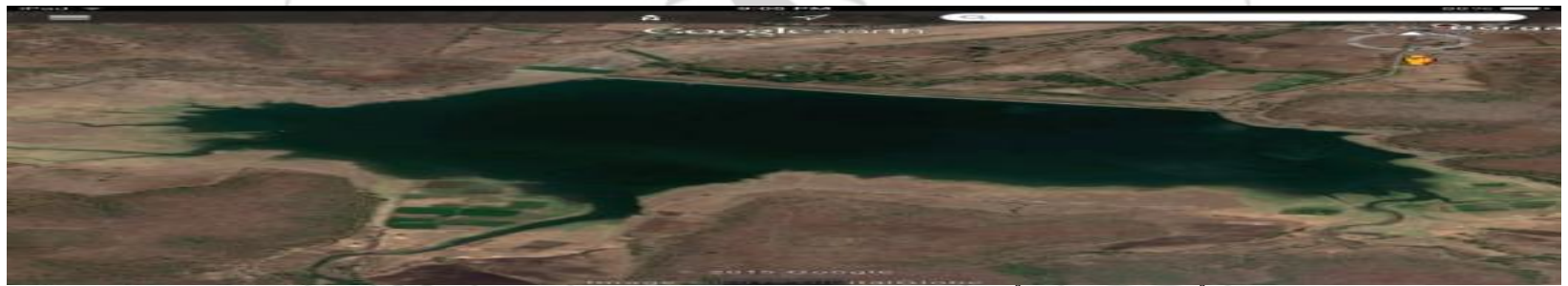

Figure 5: Location of Borgaon Dam(Medium Project) $-78^{0}-17^{\prime}-43^{\prime \prime}-20^{0}-27^{\prime} 16^{\prime \prime}$

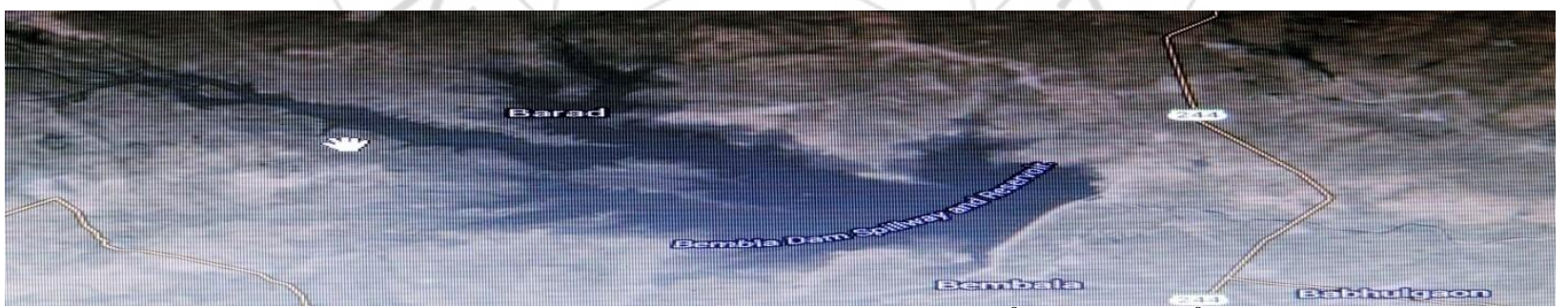

Figure 6: Location of Borgaon Dam(Medium Project) $-78^{0}-14^{\prime}-43^{\prime \prime}-20^{\circ}-18^{\prime} 24^{\prime \prime}$

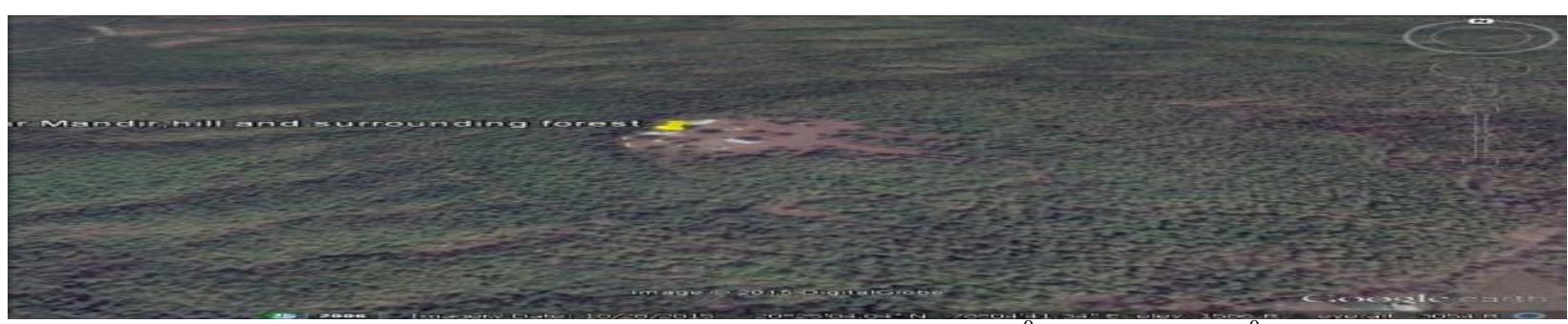

Figure 7: Location of Chousala forest range(Hill and Mandir)- $78^{0}-04^{\prime}-41.43^{\prime \prime}-20^{\circ}-25^{\prime}-04.04$ '"

A pair of Binoculars 8 x 40(Nikon) and Digital (fixed lance) Camera (Nikon Coolpix-520) and GPS instrument were used for observations, photography as well as location record respectively. Naoroji (2013) and Grewal B et al (2011) were used for field identification and residential status. Species with scientific details are given in the Table 1 . Within the given habitat, transects were established about $500 \mathrm{~m}$ long and $50 \mathrm{~m}$ wide. The data were analyzed using Shannon Wiener function formula; species diversity $(\mathrm{H})$, maximum diversity (Hmax), and evenness (E)

\section{Volume 5 Issue 5, May 2016}

www.ijsr.net 


\section{International Journal of Science and Research (IJSR) \\ ISSN (Online): 2319-7064}

Index Copernicus Value (2013): 6.14 | Impact Factor (2015): 6.391

$$
\mathrm{H}=\sum_{\mathrm{i}=1}^{\mathrm{S}}-\left(\mathrm{P}_{\mathrm{i}} * \ln \mathrm{P}_{\mathrm{i}}\right) \quad \mathrm{H}_{\max }=\operatorname{logs} \quad \mathrm{E}=\mathrm{H}^{\prime} / \mathrm{H}_{\max }
$$

\section{Result and Discussion}

The study has based on survey, observations and sighting records of raptors from study area like Borgaon dam,
Jamwadi dam, Nilona dam, Chuasala forest, Bemla dam, Echori forest and Bahiram forest that were situated around the Yavatmal city, Maharashtra, central India. (Table-2) Twenty raptors were observed during study period and categorizing as per Taxonomical status and Sighting/use ecosystem.(Table-1)

Table 1: Species and their population in the different ecosystem used during the study period

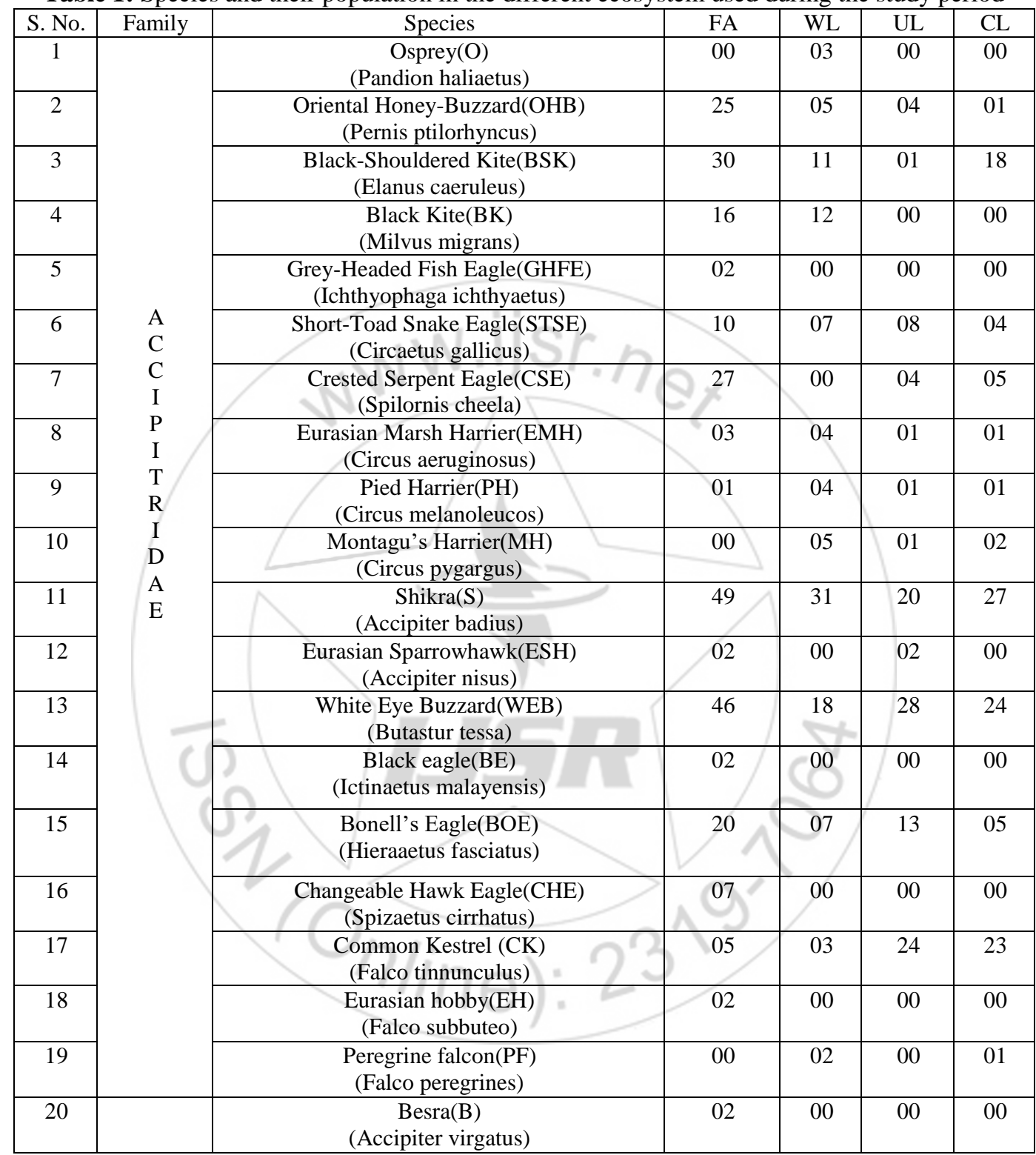

Year Dec. 2014- Dec.2015.Areas-- FA-Forest Area, WL- Wet Land, UL- Unplowed Land, CL- Cultivated Land.

The study established that the Sikra and White-eye buzzard are sizable number from all the selected area. The adversely affected raptors like Grey-headed fish eagle, Black eagle, Besra, Peregrine falcon, Osprey and Eurasian hobby were rarely observed. Similarity indicated a trend of fragmentation in the area, with the various fragments at different levels of degradation directly affects the majority of raptors, which were, recorded not more than ten times Table-2 and Graph-2. The highest population was sighted in the forest area followed by wetland, cultivated land and lastly unplowed lands, which are, indicates in the graph 1. 
International Journal of Science and Research (IJSR)

ISSN (Online): 2319-7064

Index Copernicus Value (2013): 6.14 | Impact Factor (2015): 6.391

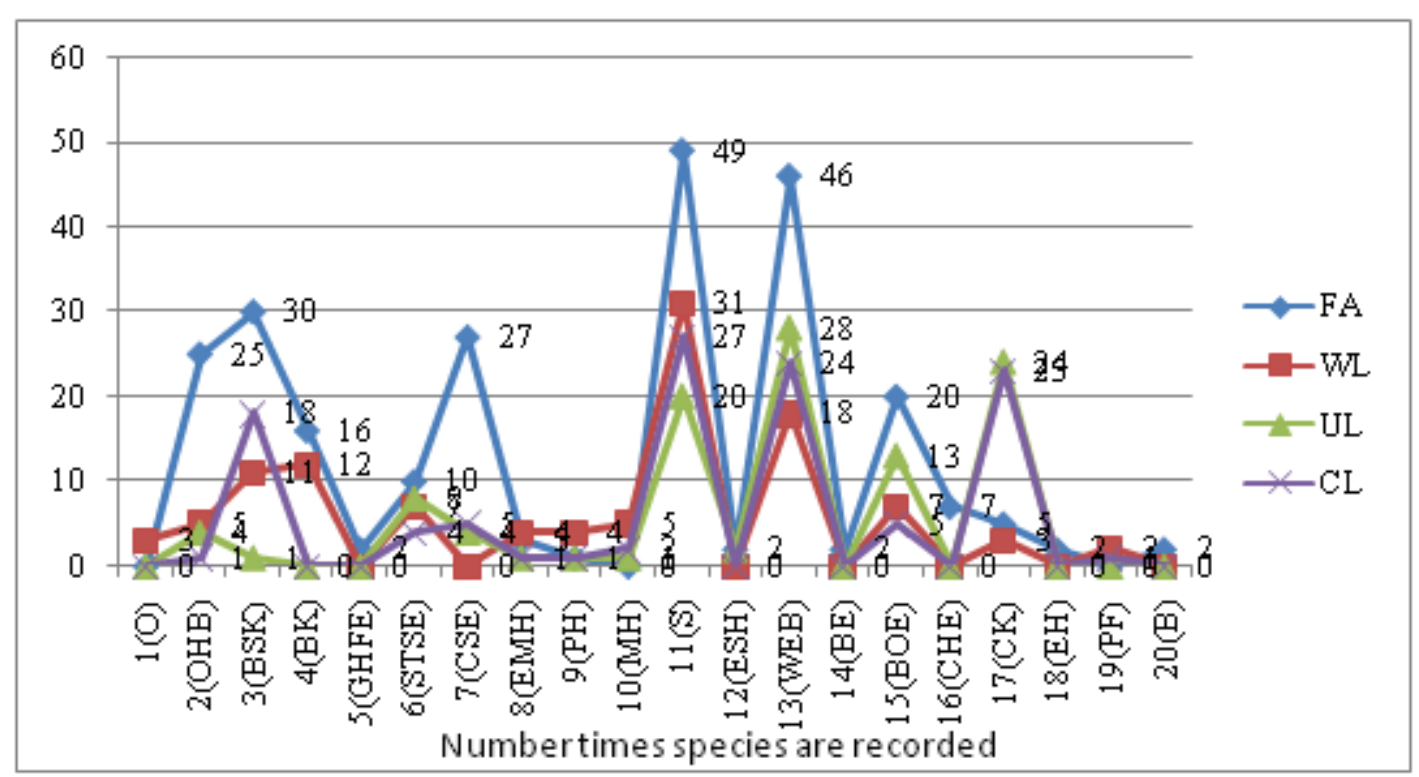

Graph 1: Areas-- FA-Forest Area, WL- Wet Land, UL- Unplowed Land, CL- Cultivated Land.

Table 2: Species and their population in the different ecosystem used during the study period year 2013-2015

\begin{tabular}{|c|c|c|c|c|c|c|c|c|}
\hline Species & \multicolumn{7}{|c|}{ Area } & \multicolumn{1}{c|}{ Total } \\
\cline { 2 - 8 } & Bf & Nd & Ef & Jd & Bd & Be.d & Cf & \\
\hline $1(\mathrm{O})$ & 00 & 01 & 00 & 00 & 00 & 02 & 00 & 03 \\
\hline $2(\mathrm{OHB})$ & 08 & 00 & 02 & 04 & 06 & 05 & 10 & 35 \\
\hline $3(\mathrm{BSK})$ & 10 & 10 & 04 & 10 & 11 & 09 & 06 & 60 \\
\hline $4(\mathrm{BK})$ & 03 & 06 & 02 & 04 & 07 & 01 & 05 & 28 \\
\hline $5(\mathrm{GHFE})$ & 00 & 00 & 02 & 00 & 00 & 00 & 00 & 02 \\
\hline $6(\mathrm{STSE})$ & 02 & 10 & 02 & 04 & 01 & 03 & 07 & 29 \\
\hline $7(\mathrm{CSE})$ & 03 & 05 & 04 & 14 & 03 & 01 & 06 & 36 \\
\hline $8(\mathrm{EMH})$ & 00 & 02 & 03 & 01 & 00 & 01 & 02 & 09 \\
\hline $9(\mathrm{PH})$ & 00 & 01 & 01 & 00 & 00 & 03 & 02 & 07 \\
\hline $10(\mathrm{MH})$ & 00 & 03 & 02 & 00 & 01 & 02 & 00 & 08 \\
\hline $11(\mathrm{~S})$ & 20 & 32 & 14 & 36 & 10 & 05 & 10 & 127 \\
\hline $12(\mathrm{ESH})$ & 00 & 00 & 02 & 00 & 01 & 01 & 00 & 04 \\
\hline $13(\mathrm{WEB})$ & 20 & 10 & 21 & 18 & 19 & 12 & 16 & 116 \\
\hline $14(\mathrm{BE})$ & 01 & 00 & 00 & 00 & 01 & 00 & 00 & 02 \\
\hline $15(\mathrm{BOE})$ & 05 & 16 & 00 & 10 & 04 & 05 & 05 & 45 \\
\hline $16(\mathrm{CHE})$ & 03 & 00 & 00 & 02 & 00 & 00 & 02 & 07 \\
\hline $17(\mathrm{CK})$ & 05 & 10 & 12 & 03 & 12 & 08 & 05 & 55 \\
\hline $18(\mathrm{EH})$ & 00 & 00 & 00 & 00 & 00 & 00 & 02 & 02 \\
\hline $19(\mathrm{PF})$ & 00 & 00 & 00 & 00 & 00 & 02 & 01 & 03 \\
\hline $20(\mathrm{~B})$ & 00 & 00 & 00 & 00 & 02 & 00 & 00 & 02 \\
\hline
\end{tabular}

Location: Bf-Bahirum forest, Nd- Nilona dam, Ef- Echori forest, Jd-Jamwadam, Bd-Borgaon dam, Be.d- Bembala dam and Chuasala forest. Details of species abbreviations given in table-1 
International Journal of Science and Research (IJSR)

ISSN (Online): 2319-7064

Index Copernicus Value (2013): 6.14 | Impact Factor (2015): 6.391

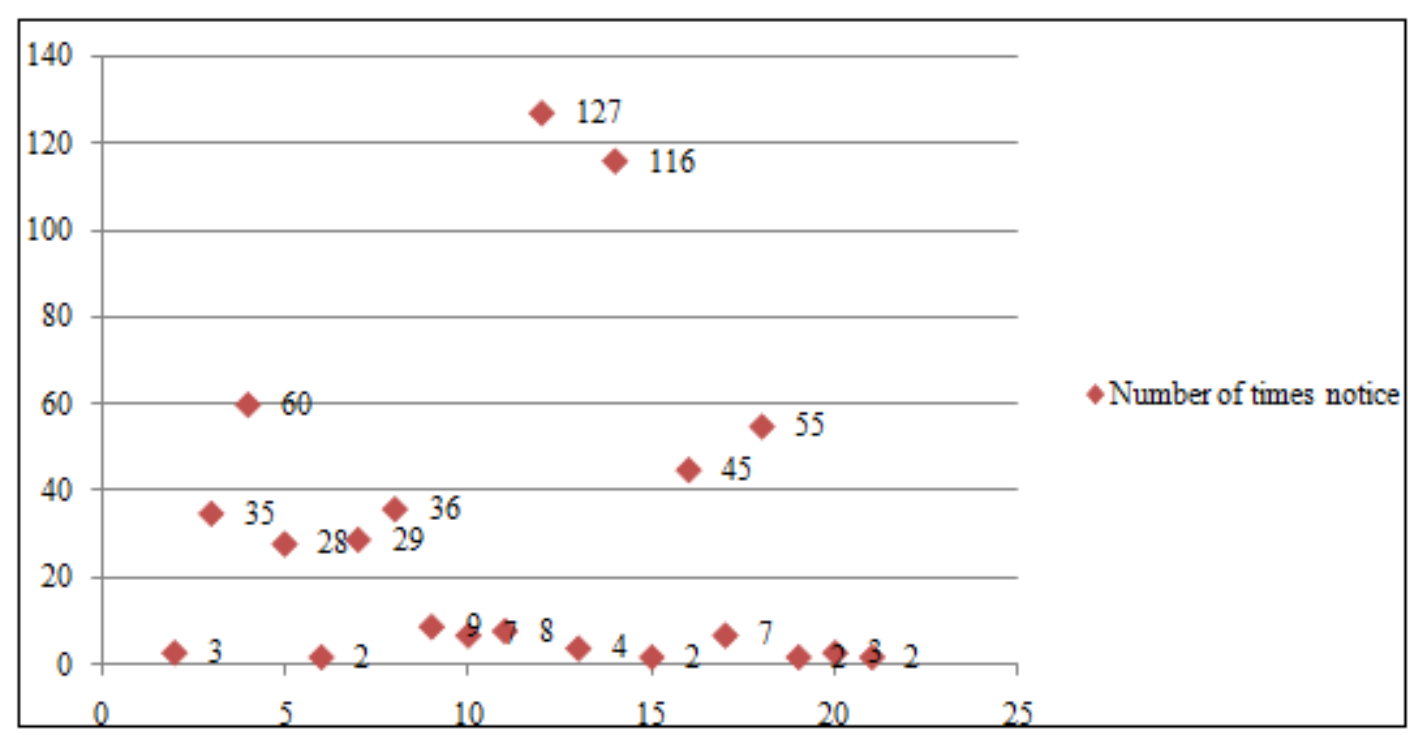

Graph 2: indicates number of times raptors are observed. (Details of abbreviation are given in Table-1)

The findings has used for analyzing the Shannon-Wiener function formula. The results are as follows species diversity (H-2.35), maximum diversity (Hmax-2.99) and evenness (J0.78 ). The formula are implemented individually to different habitat and results are indicates that FA having Species diversity (H-2.31), maximum diversity (Hmax-2.99) and evenness (E-0.77). WL -Species diversity (H-2.62), maximum diversity (Hmax-2.99) and evenness (E-0.87), UL- Species diversity ( $\mathrm{H}-1.85$ ), maximum diversity (Hmax-2.99) and evenness (E-0.61). CL- Species diversity (H-1.81), maximum diversity (Hmax-2.99) and evenness (E0.60). (Table-1 and Table2). The above observations indicate that the area including dam and forest supports at least 20 raptor and most of them are feeding diverse food that are abundantly available in the area. In this study, we provided evidence on the response of raptors to certain structural attributes of selected lands. The primary results will provide base line data that helps to motivate the study of occurrence and flyways migration pattern of raptors over the fresh water bodies and forest of Yavatmal city and their surrounding area, Central Asia. The results of my work suggests that following the approach of selected ecosystem and the diversity index formula should be established correlation for both i.e. bird of prey and conservation needs.
[9] Rishad Naoroji (2012): Bird of prey of the Indian subcontinent, OM Book Service,India

\section{References}

[1] Ali,s. (1996) :The Book of Indian Birds, $12^{\text {th }}$ edn. New Delhi: BNHS \& OUP.

[2] Ali, S. \& Riplay,D.(1987): Hand book of the birds of India \& Pakistan, compact edn. Bombay:OUP

[3] Grewal, B. (2011): Birds of Indian sub continent (Third Edition) Hong Kong: Guide book co. Ltd.

[4] Grimmett, R., Inskipp C. and Inskipp, T. (2000) Birds oh Indian subcontinent. London.

[5] John Hendrickson (1992) Bird of Prey China.

[6] Manakdan Ranjit and Daniel J.C. et al (2011) Birds of Indian subcontinent A field Guide. Oxford University Press, USA.

[7] Martin Woodcock (1983) Collins Birds of India, Harper Collins UK.

[8] Otto pfister (2011) A Photographic guide of birds of India. Timeless book New Delhi. 